\title{
RESIDENCE TIME DISTRIBUTION-BASED ANALYSIS OF AN INDUSTRIAL-SCALE BIOGAS FERMENTER
}

\author{
ANDRÁs TANKOVICS ${ }^{1}$, DÁvId TAKÁCS ${ }^{1}$, JUdIT SZENDEFY², BÉla CSUKÁS ${ }^{1}$, AND MÓNIKA \\ VARGA*1 \\ ${ }^{1}$ Institute of Methodology, University of Kaposvár, Guba Sándor u. 40, Kaposvár, 7400, HUNGARY \\ ${ }^{2}$ Biogas Plant, Magyar Cukor Zrt., Pécsi u. 10, Kaposvár, 7400, HUNGARY
}

\begin{abstract}
Residence Time Distribution (RTD) measurement-based analysis of mixing conditions on an industrial-scale $(13,000$ $\mathrm{m}^{3}$ ) anaerobic digester of pressed sugar-beet slices at Kaposvár Sugar Factory of Magyar Cukor Zrt. was studied. The lithium salt tracing technique was applied, while the quantity of the lithium chloride tracer and the sampling of the effluent were designed by a preliminarily studied simulation model of mixing. The lithium concentration at the outlet was analysed by Inductively coupled plasma-optical emission spectroscopy (ICP-OES). Taking into account the geometrical arrangement, the biogas flow produced and the cyclically changing recycle flow, various mixing models were generated with different compartmentalization and flow structures by applying the method of Programmable Process Structures. The simulation-based approximate identification of the mixing model was accomplished by a heuristic approach that took into consideration multiple structures with changing mixing flows. A model with an advantageously small number of compartments and parameters was sought which satisfies the measured RTD. The results suggest the intensive mixing of upper levels with a poorly mixed lower level, which contributes to the long tail in the RTD. The actual set-up supports a good horizontal distribution of the sugar-beet slices and the microbial biomass, while the limited degree of vertical mixing helps to avoid the elutriation of the useful microbiome. The suggested mixing model will be combined with the formerly elaborated model involving 9 bacterial groups.
\end{abstract}

Keywords: anaerobic digestion, mixing of digester, Residence Time Distribution, lithium tracing, Programmable Process Structures

\section{Introduction}

The mixing of anaerobic digesters is a critical issue because it should support the uniform distribution of raw materials to be digested and the bacterial biomass along the cross-section of the unit. Moreover, the excessive sedimentation of the solid (bacterial) phase at the bottom of the digester should be avoided. However, an unnecessarily high degree of mixing may elutriate the bacterial biomass that decreases the effectiveness of transformations and may cause surplus environmental load.

The computational modelling of anaerobic digesters was developed from the modelling of wastewater treatment and degradation [1,2] and from the ADM models designed by IWA $[3,4]$. A comprehensive review from 2013 is available [5].

Knowledge about mixing in large biogas digesters is still in its infancy, so the objective of this study is to broaden this by determining the minimum retention time of substrates fed into anaerobic digesters and estimate the distribution time of substrates before being extracted from the investigated digester.

\footnotetext{
*Correspondence: varga.monika@ke.hu
}

Over the last century, compartmentalized models were successfully used given the lack of computational fluid dynamics (CFD) models available, e.g. for studying an interesting scale-up problem, where the partially mixed pilot performed better than the perfectly mixed laboratory unit [6]. Moreover, at that time, a review comparing compartmentalization with CFD was published [7] which concluded that CFD is the most scale-independent method for mixing and scale-up studies, however, it is hampered by limitations such as high computational demands and the inadequacy of submodel consideration, e.g. biokinetics.

In a recently published detailed review [8], the authors concluded that "Compartmental models allow multi-scale modelling with low computational time compared to a full coupled model (e.g. reactive numerical simulations). Thanks to these main characteristics, compartmental models are able to model complex full-size industrial systems. An effective compartment model could handle multiple, multiphysics phenomenological models (detailed kinetic reaction scheme, complex heat and mass transfer model, population balance, etc.) that could not be included in CFD analysis. Observed deviation between 
fully detailed CFD model and compartment model show very small results deviation despite of very significant reduction in calculation time ( 3 orders of magnitude)."

An interesting new example of a hypothesis-driven compartmental model is given in [9].

Two full-scale digesters from a biogas plant $(2,000$ $\mathrm{m}^{3}$ and $1,500 \mathrm{~m}^{3}$ ) equipped with different mixing systems and filled with different substrates were investigated by Kamarad et al. [10]. To characterize the substrate distribution, solutions of lithium hydroxide monohydrate were used in tracer tests at concentrations of $45-50 \mathrm{mg}$ $\mathrm{Li}^{+} / \mathrm{kg}$ TS in digesters. The tracer concentration in the effluent of the digester was measured. Although the data calculated by CFD methods were in very good agreement with the results, a full comparison was not made

Kaposvár Sugar Factory of Magyar Cukor Zrt. developed an internationally straightforward anaerobic fermentation technology to generate onsite used and surplus energy with a reduced amount of waste emitted by producing fuel gas of high methane content from the pressed sugar beet slices. In a former $\mathrm{PhD}$ thesis [11], a detailed simulation model was developed and validated for an approximately perfectly mixed pilot unit that took into consideration 9 pseudogroups of bacteria by applying the available earlier version of Direct Computer Mappingbased modelling methodology.

The scaling up of the model to an industrial scale [12] requires more detailed knowledge about the hydrodynamic conditions of the appropriately compartmentalized volume. The objective of this work was to measure and analyse the Residence Time Distribution of a large industrial unit by a lithium tracer technique. The final goal of this analysis was to embed the formerly developed detailed digestion model into the compartmentalized mixing model to enhance the investigated fermenter.

\section{Experimental work}

The industrial digester (see Fig. 1) was a cylindrical unit with a diameter of $25 \mathrm{~m}$ and height of $28 \mathrm{~m}$. The effluent was removed from a volume of approximately $13,000 \mathrm{~m}^{3}$ at a level of $20 \mathrm{~m}$.

Spatially uniform feeding and appropriate mixing was ensured by the recycle flow from a level $20 \mathrm{~m}$ in height from the base of the unit and fed into the annularly placed 6 subsequent bottom segments with a prescribed cyclic change of the flow. The pressed sugar beet slices were also fed into this recycle flow via a screw feeder. Mixing was enhanced significantly by the increasing upward flow of the generated biogas. Moreover, three small mechanical mixers ensured the raw materials and bacteria were uniformly distributed in the lower third of the unit. The slowly accumulating inorganic residue could be removed from the middle of the bottom of the digester by means of a slowly rotating agitator.

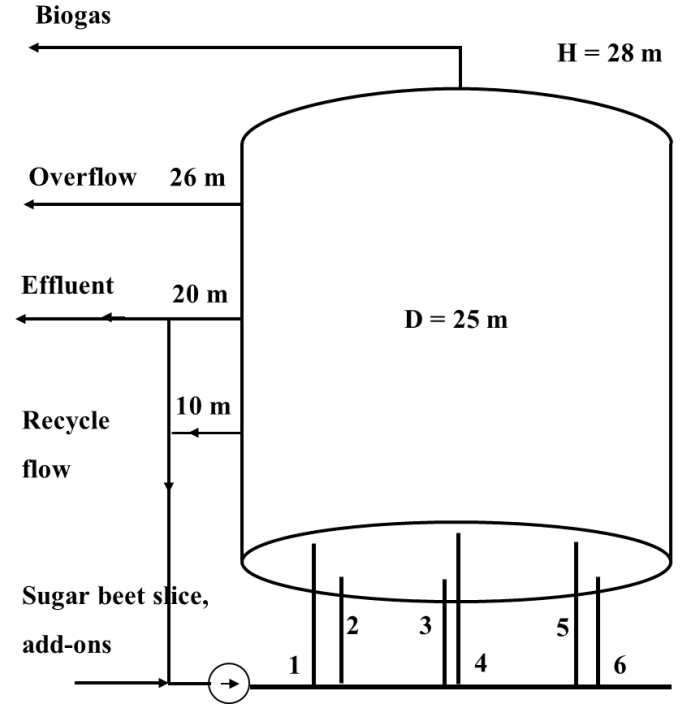

Figure 1: Schematic diagram of the industrial-scale fermenter of $13,000 \mathrm{~m}^{3}$ in volume

\subsection{Tracing and Measurement Technique}

For the tracing of the flow, $40 \mathrm{~kg}$ of lithium chloride p.a. was dissolved in 150 litres of tap water. Considering the contamination of sugar beet slices with many ions, lithium was chosen given the sensitivity of its measurements. A blank sample was tested and a calibration prepared by adding known amounts of lithium chloride to the blank solution of realistic composition. This amount was added to the sludge flow of fresh sugar beet slices at a rate of $43 \mathrm{~m}^{3} / \mathrm{h}$ on average. The duration of tracing was 150 seconds, while the main recycle flow was switched off during this time. Before and after the tracer inlet, the recycle flow was maintained at $200 \mathrm{~m}^{3} / \mathrm{h}$.

Differing from the geometrically arranged order of annular segments 1-2-3-4-5-6, the actually applied order of feeding was 1-2-(3)-6-4-5, while during the experiments the inlet to segment \#3 was closed (because of a malfunctioning valve). Accordingly, the cyclic feeding sequence was changed to 1-2-6-4-5 over 360 seconds.

The tracer was fed into segment 4 , while the samples were taken from the effluent and discharged from segment 5 at a height of $20 \mathrm{~m}$. The draft samples of 1-2 litres in volume were filtered before being analysed.

The concentration of $\mathrm{Li}^{+}$was measured by the ICPOES spectrometer at Kaposvár University.

\subsection{Modelling and Simulation Methodology}

For the modelling and simulation of the flow structure of the fermenter, the methodology of Programmable Process Structures (PPS) was applied $[9,10]$.

In PPS (see Fig. 2), the locally programmable structure of process models could be generated from two general meta-prototypes and from the standardized description of the actual process network automatically, resulting in the dynamic structure of unified state and transition 


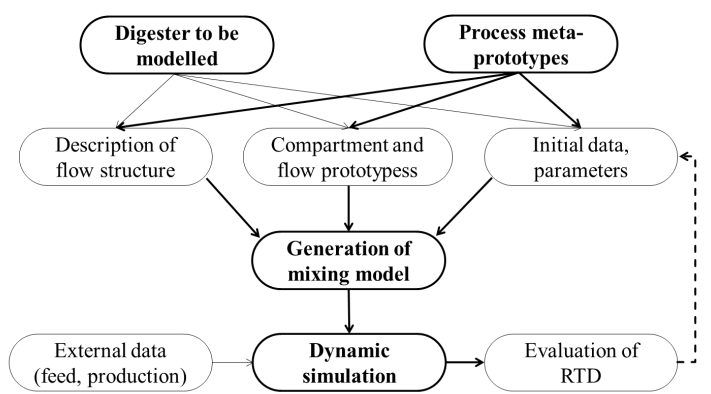

Figure 2: Schematic diagram of the generation of the process model by the method of Programmable Process Structures

elements. The prototype elements, which describe the functionalities of the model, could also be derived from the general meta-prototypes. The freely editable, actual prototype programs contain symbolic input, parameter and output variables as well as a locally executable program code. In various applications, many state and transition elements can be modelled with the same or similar, reusable local programs (referred to as actual prototypes). The state and transition elements of the actual model can be parameterized and initialized concerning their casespecific prototypes. Its execution, namely connectionbased communication between the state and transition elements of the programmed structure, is solved by the general-purpose kernel program of the method.

During the simulation, the actual elements are initialized by initial conditions and parameters, moreover, the output values are recalculated stepwise by taking into consideration input and parameter data according to the associated local program prototype. The identified input and output connections of the extensive/intensive properties and signals make the combined execution of the balance-based and signal-based functionalities possible.

\section{Results and Analysis}

\subsection{Experiments}

The quantity of the lithium chloride tracer $(40 \mathrm{~kg})$ and the sampling of the effluent during the measurement of the RTD were designed by some preliminarily studied, approximate mixing models. The concentration of lithium chloride in the effluent was measured every $0.5-2$ hours during the first period and daily or even less frequently over the following 23 days (when production slowed down by ending campaign). The data are summarized in Table 1 and in Fig. 3.

\subsection{Possible Flow Structures and Parameters}

By taking into consideration the geometrical layout, the produced biogas flow and cyclically changing recycle flow, various mixing models with different compartmentalization and flow structures were generated by applying the method of Programmable Process Structures.
Table 1: Measured concentrations of lithium chloride in the effluent

\begin{tabular}{cccc}
\hline Sample ID & Date & Time, hours & $\mathrm{Li}^{+}, \mathrm{mg} / \mathrm{l}$ \\
\hline 0 & Blind & 0 & $<0.100$ \\
1 & 2018.12 .18 & 0.5 & $<0.100$ \\
2 & 2018.12 .18 & 1 & 0.226 \\
3 & 2018.12 .18 & 2 & 0.347 \\
4 & 2018.12 .18 & 4 & 0.311 \\
5 & 2018.12 .18 & 6 & 0.237 \\
7 & 2018.12 .18 & 8 & 0.811 \\
8 & 2018.12 .19 & 26 & 0.627 \\
9 & 2018.12 .19 & 38 & 0.538 \\
10 & 2018.12 .20 & 48 & 0.625 \\
11 & 2018.12 .22 & 96 & 0.536 \\
12 & 2018.12 .24 & 144 & 0.401 \\
$12 \mathrm{~B}$ & 2018.12 .26 & 192 & 0.516 \\
13 & 2018.12 .28 & 240 & 0.423 \\
14 & 2019.01 .02 & 360 & 0.325 \\
15 & 2019.01 .04 & 408 & 0.361 \\
16 & 2019.01 .07 & 480 & 0.384 \\
17 & 2019.01 .10 & 552 & 0.323 \\
& & &
\end{tabular}

The most detailed compartmentalization (D1) is shown in Fig. 4. Here the sludge zone of the process unit was divided into three vertical layers which were divided further into an inner cylinder, surrounded by an annulus that was divided into six parts.

The mixing flows between the 21 (approximately perfectly mixed) compartments are as follows:

- Circflowmix: cyclically changing recycle flow, superposed by a bidirectional mixing flow between the annular slices above each other;

- Gasflowmix: bidirectional mixing flow, induced by the upward biogas flow between the compartments above

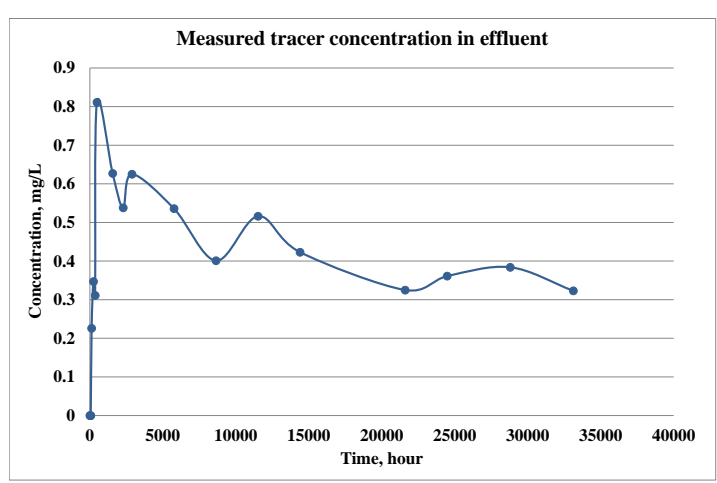

Figure 3: Measured tracer concentration of $\mathrm{Li}^{+}$in the effluent of the industrial-scale fermenter $(40 \mathrm{~kg}$ of lithium chloride dissolved in 150 litres of tap water was added to a sludge of sugar beet slices that entered segment \#4 at a flow rate of $43 \mathrm{~m}^{3} / \mathrm{h}$ for 150 seconds) 


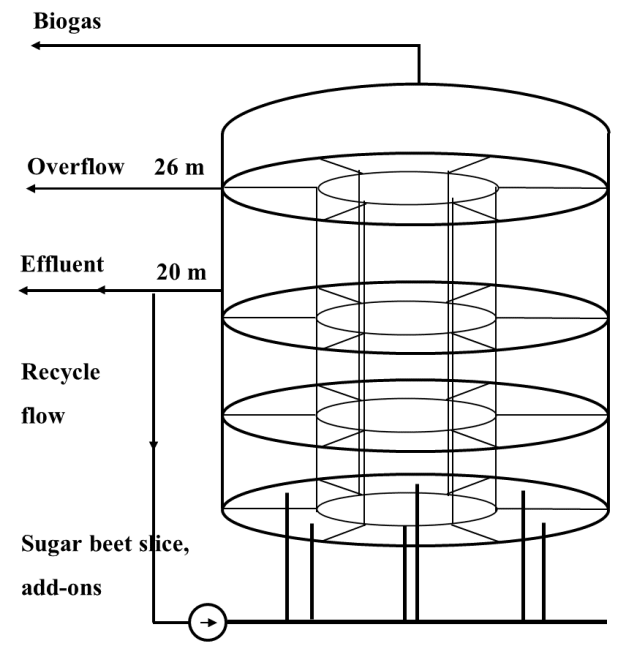

Figure 4: The most detailed schematic diagram of the fermenter (Scheme D1).

each other (for practical considerations, circflowmix and gasflowmix can be integrated into a single flowmix);

- Permix: peripheral bidirectional mixing flow between the subsequent annular slices of the same layer, horizontally;

- Radmix: radial bidirectional mixing flow between the annular slices and the inner cylinder of the same layer, horizontally.

The flow rate of the biogas increased as the height of the unit increased. Accordingly, gasflowmix was higher between layers 2 and 3 than between 1 and 2 .

It is worth mentioning that the outflow rate of the effluent was considerably less than the inflow rate of the sludge composed of pressed sugar beet slices because a significant proportion of the raw material was converted into biogas that escaped through the upper gas dome.

In Scheme D2 (Fig. 5 which was finally proven to be the best solution), the inner cylinder and the related vertical and horizontal mixing flows were removed because they slowed down the mixing in Scheme D1 by an unfeasible degree.

As a further simplification, the upper layer was not decomposed at all. It should be noted that an interaction between the changes in the structures and their parameters exists. As an example, Scheme D3 (Fig. 6) behaved in a similar way to D2 with the highest horizontal mixing flows in the upper layer. Planned future research will focus on using less compartments which might also be advantageous in terms of embedding the detailed dynamic model of anaerobic digestion into the flow structure. Accordingly, Scheme D4 (Fig. 7) was also tested, where only the lower layer was decomposed.

As a marginal solution, the case of Scheme D5 (Fig. 8) was also studied with only vertical decomposition of the process unit.

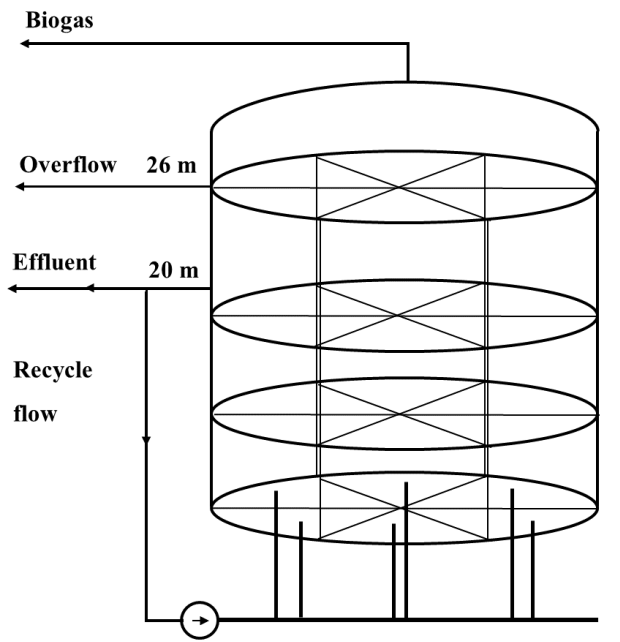

Figure 5: Schematic diagram of the best performing fermenter (Scheme D2).

\subsection{Generation of the Simulation Models}

The process network of the various schemes can be defined by a general declarative program. A characteristic part of the definitions of Scheme D2 is as follows:
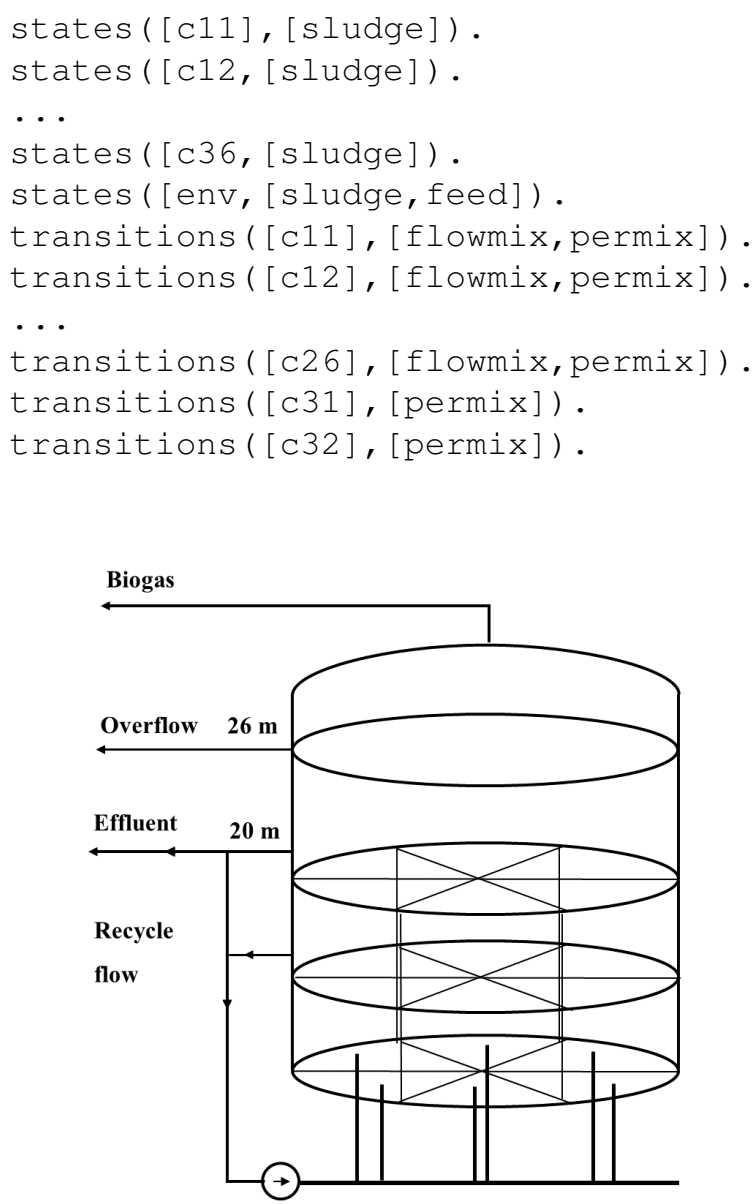

Figure 6: Simplified schematic diagram of the fermenter without decomposition of the upper layer (Scheme D3). 


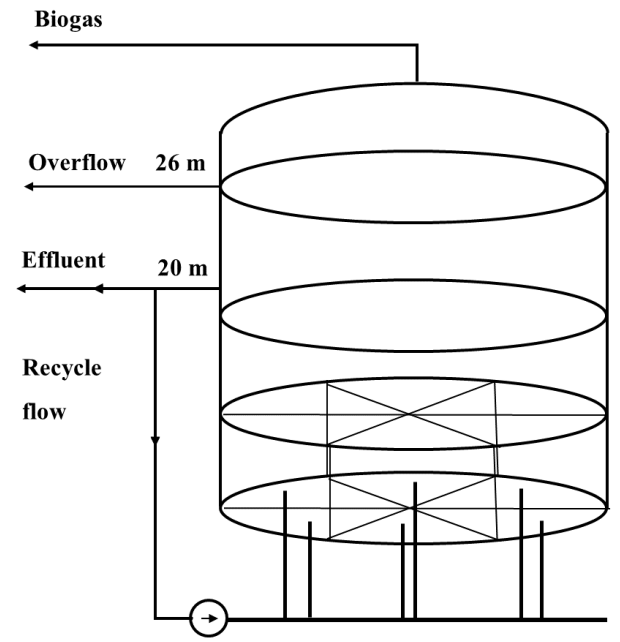

Figure 7: A more simplified schematic diagram of the fermenter (Scheme D4).

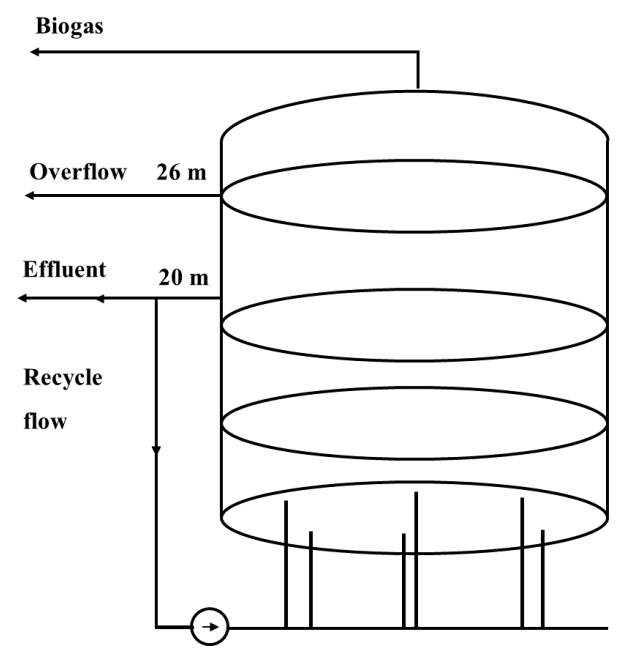

Figure 8: Trial in the absence of horizontal compartmentalization (Scheme D5).

. .

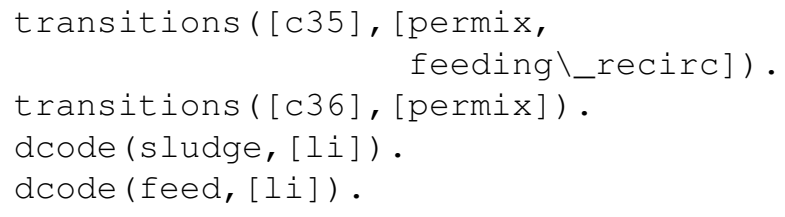

where states and transitions are declared by the state and transition elements in the given compartments, respectively. Meanwhile, the lowest level components of the state elements are described by the dcode () predicates.

The transition-based representation of the flow structure is defined by the facts of predicate:

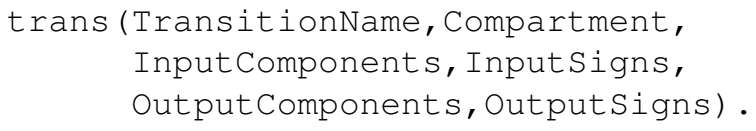

For example,

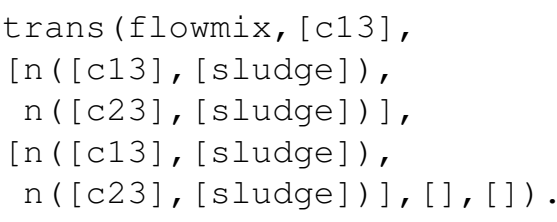

generates bidirectional connections for mixing flows between compartments [c13] and [c23] of the first and second layers, respectively. Similarly,

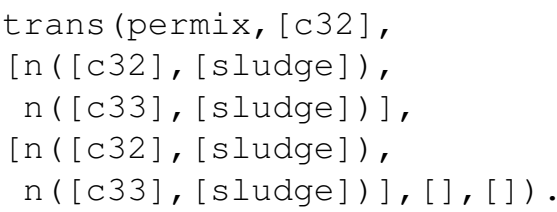

generates peripheral flows between compartments [c32] and [c33] in the third layer.

The initial concentrations and parameters of the various state and transition elements were recorded in an MS Excel file from where they were transformed into a textual form of declarative predicates.

According to Fig. 2, the automatic generation of the Programmable Process Structures was conducted:

- from the two general prototypes $[9,10]$,

- from the textual description of the actual process network, and

- from the textual declaration of initial values and parameters.

The automatically generated structural model of Scheme D2 is illustrated in Fig. 9.

\subsection{Local Programming of the Generated Process Structure}

The functionalities of the flow-structure models can be represented by locally executable programs embedded in the prototype elements. The prototype elements can be prepared from the copies of the meta-prototypes, e.g. the local program for the calculation of flowmix is presented below:

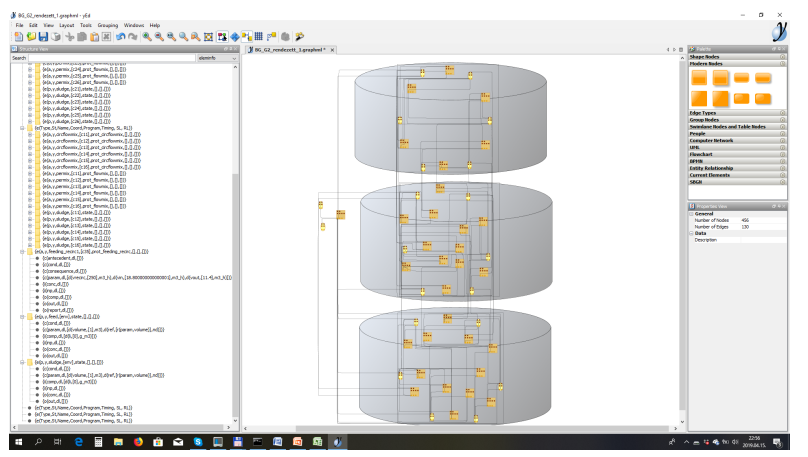

Figure 9: Programmable Process Structure of Scheme D2. 


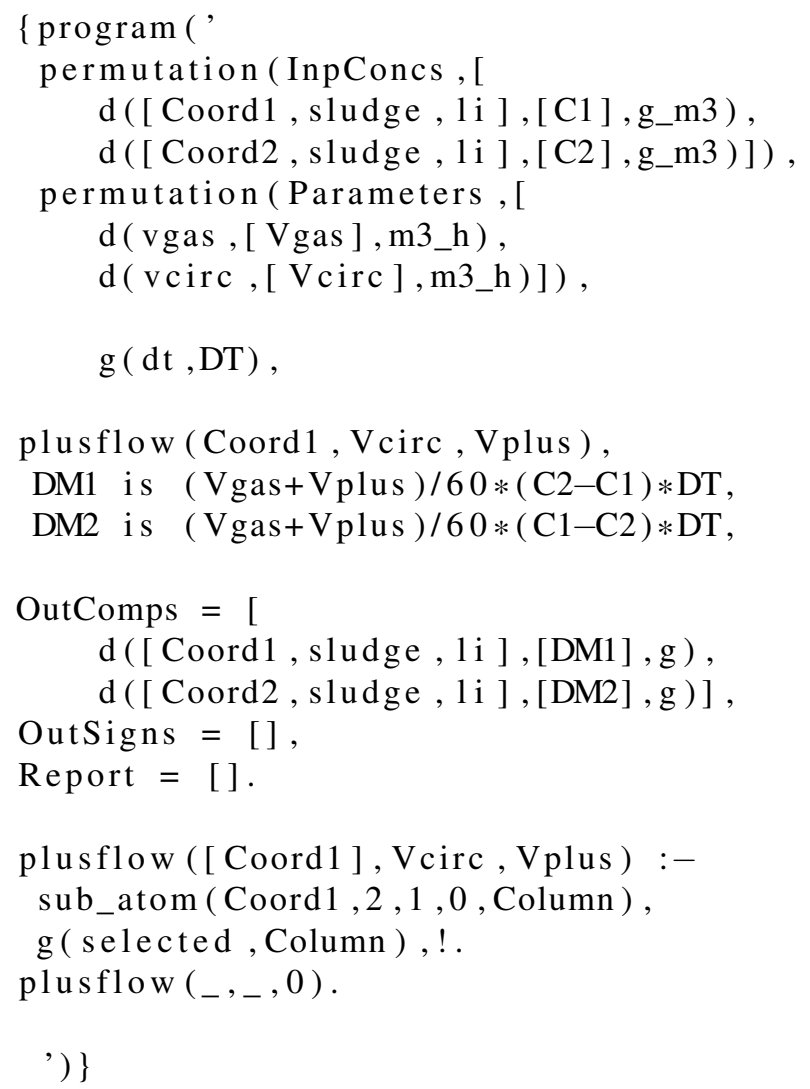

This program illustrates how the input, parameter and output data are represented by the unified d(Identifier, List_of_Values, Dimension) triplets.

The input data for calculations originated from the respective compartments Coord1 and Coord2. The parameters define the Vgas mixing flow associated with the gas flow and the Vplus mixing flow generated by the recycle upflow between the given vertical segments. The actually active segment was determined by the integer value of Column in the $g$ (selected, Column) global predicate (which was actualized by another local program, responsible for the cyclic switching of the recycle flow).

The auxiliary clause plusflow () considers mixing flow Vcirc only if the recirculation is actually associated with the given compartments, otherwise the surplus mixing is equal to zero.

The Out Comps output of the program forwarded the changes in the amount of tracing component DM1 and DM2 in the compartments Coord1 and Coord2, respectively.

\subsection{Evaluation of the RTD Measurements}

The mass flow of the produced biogas was calculated from the measured total volumetric flow rate of the three parallel operating digesters, divided according to the individually measured loads of sugar beet slices of the parallel lines whilst taking into consideration the measured composition of the biogas. The slightly changing output

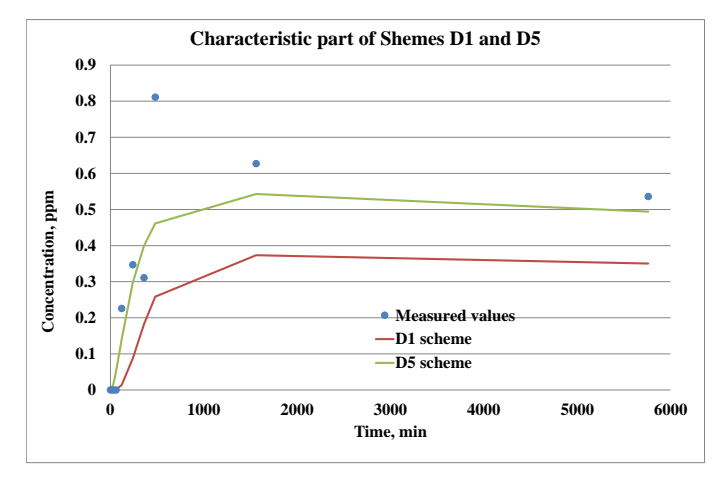

Figure 10: Initial period of Scheme D1 that was insufficiently mixed and Scheme D5 that was overmixed.

flow of the effluent was calculated from the changing load and biogas mass flows.

Regarding the identification and validation of the multiple structure, it must be emphasized that this task was underdetermined. Considering the multiple interactions between the structures and parameters, instead of a rigorous optimization procedure, a heuristic trial and error approach was applied, controlled by the main features first and then the values of the normalized root mean square error (NRMSE) in the refinement. The evaluation was effectively aided by monitoring the change in concentrations in each compartment.

First, D1 (being insufficiently mixed) and D5 (being overmixed) were excluded as can be seen in Fig. 10. Afterwards, D2-4 were studied and based on the calculated NRMSE values, D3 and D4 were stepwise rejected. Finally, the parameters of D2 were refined.

The simulated and measured data are illustrated in Figs. Figs. 11-14 in addition to the calculated NRMSE values.

Fig. 10 (and many trials using other parameters) showed that even Schemes D3-5 were unable to model the evident initial peaks of the measurements.

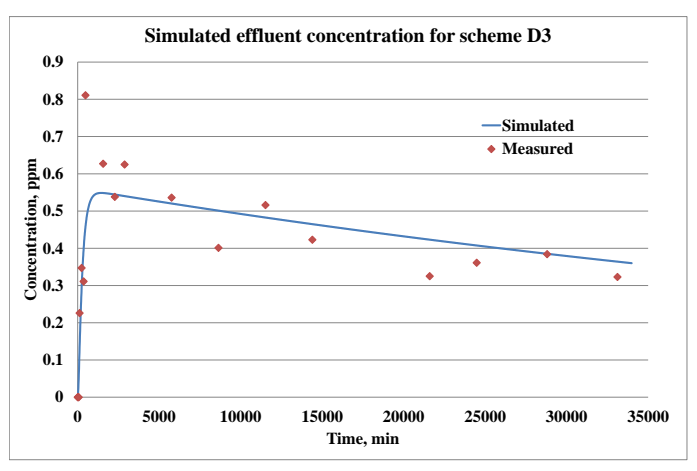

Figure 11: Trial using horizontal compartmentalization in two lower layers only (Scheme D3, NRMSE $=12.10 \%$ ). 


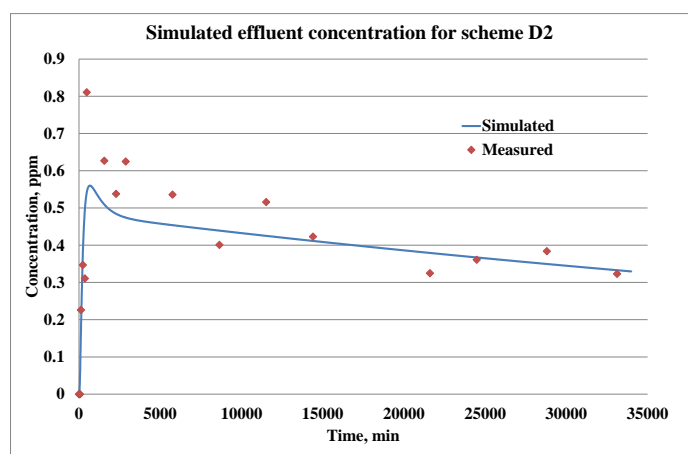

Figure 12: Trial using horizontal compartmentalization in three layers (Scheme D2, NRMSE $=12.08 \%$ ).

The horizontal decomposition in all layers (without an inner tube) is able to express the main features using many parameters (an example is shown in Fig. 11). Decomposition Scheme D2 (compartment volume is 685.3 $\mathrm{m}^{3}$ ) with improved parameterization describes the measured data better (see Fig. 12).

The change in the concentration in the various compartments (except for the traced bottom and output top ones) is shown in Fig. 13. This shows that because of the changing input bottom compartment of the recycle flow, the initial peak in concentration does not appear in each compartment.

The long tail is partly a consequence of the great difference between the input feed and output effluent flows as well as of the limited degree of mixing between the layers and annular zones (especially in the bottom layer). It is also worth noticing the constant difference in concentration in the compartments. Unfortunately, the continuation of measurements was limited by the closing end of the campaign. Moreover, were they to continue, the sensitivity of the concentration measurements would decrease far below $0.3 \mathrm{ppm}$.

The computation time, depending on the number of

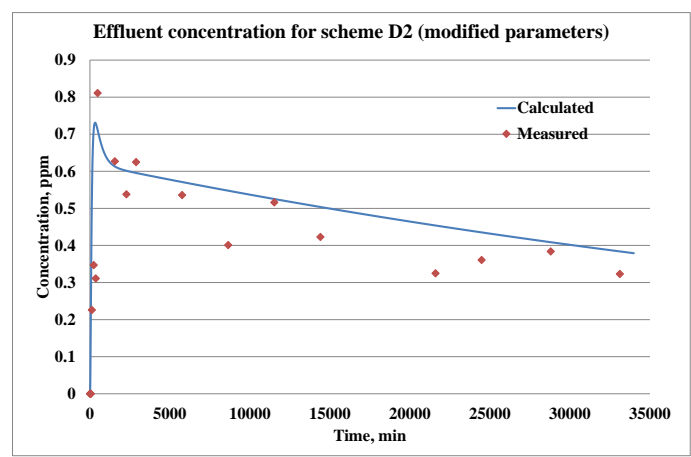

Figure 13: Scheme D2 with a feasible parameter set $($ NRMSE $=21 \%)$.

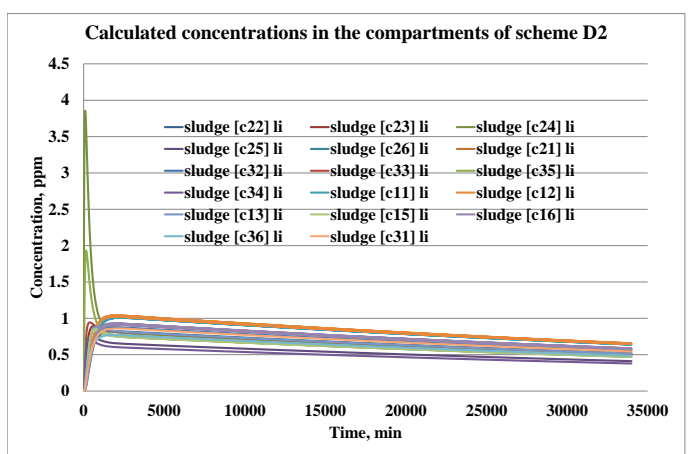

Figure 14: Change in concentration in the various compartments of the experiment shown in Fig. 12.

compartments and the flow structure, was between 2 and 90 minutes but was typically less than 10 minutes. A large difference in the volume of the compartments leads to an increase in computational efforts, while an equidistant volume distribution accelerates computation.

\section{Discussion}

The results prove that the fermenter is thoroughly mixed but by no means perfectly mixed. Accordingly, detailed modelling needs to take into consideration hydrodynamics, e.g. by using mixing flows between the compartments of the volume.

It should be emphasized that an interaction between the fermentation model and mixing exists because mixing is considerably enhanced by the produced biogas. In due course, this coupling has to be taken into consideration in the final implementation of the model.

It is a specific feature of the Residence Time Distribution of anaerobic digesters that the output liquid effluent flow is much less than the input load of the fresh sugar beet sludge (because of the production of biogas). This contributes to the slowly decreasing long tail of the RTD.

By considering the approximately identified parameters, the mixing conditions can be characterized by the following features:

- In the bottom layer, no bidirectional, horizontal mixing flow occurs between the annular segments. The horizontal mixing flow between the annular segments can also be neglected in the middle layer. However, in the intensively bubbling upper layer, significant mixing occurs characterized by a flow rate of $200 \mathrm{~m}^{3} / \mathrm{h}$ between the adjacent segments.

- Regardless of the very limited horizontal mixing in the bottom and middle layers, the appropriate distribution of the fluid and solid phases is achieved by the frequent change in location of the recycle flow (and feed) between the bottom segments. 
- The estimated mixing flow rate of the vertical sludge, generated by the upward biogas flow, was $150 \mathrm{~m}^{3} / \mathrm{h}$ and $300 \mathrm{~m}^{3} / \mathrm{h}$ between the bottom \& middle and middle \& upper layers, respectively.

- The estimated vertical mixing flow rate in the changing active sites, generated by the recycle flow, was $200 \mathrm{~m}^{3} / \mathrm{h}$ between the vertically connected segments (i.e. the mixing ratio was 0.5 ).

\section{Conclusions}

The Kaposvár Sugar Factory of Magyar Cukor Zrt. has developed an internationally straightforward anaerobic fermentation technology to generate onsite used and surplus energy with decreased emissions of waste by producing fuel gas of high methane content from pressed sugar beet slices. The development of an improved computer model as well as the analysis-based development of the technology required more detailed knowledge of the hydrodynamic conditions found within the process unit. The objective of this work was to measure and analyse the RTD of the appropriately compartmentalized industrial unit of $13,000 \mathrm{~m}^{3}$ in volume.

Spatially uniform feeding and appropriate mixing was ensured by the recycle flow, fed into the annularly placed six subsequent bottom segments with cyclic changes in location. The pressed sugar beet slices were also fed into this recycle flow via a screw feeder. Mixing was enhanced significantly by the upward increasing upstream flow of generated biogas and three mechanical agitators. By considering the geometrical arrangement, produced biogas flow and cyclically changing recycle flow, various mixing models were generated with different compartmentalization and flow structures via the method of Programmable Process Structures.

A lithium salt-based tracer technique was applied, while the quantity of the lithium chloride tracer and the sampling of the effluent during the measurement of the Residence Time Distribution were designed by some preliminarily studied simulation models of mixing. The lithium chloride concentration at the outlet was initially measured every 2 hours and daily or less frequently during longer periods. The lithium chloride concentration was analyzed by ICP-OES.

For the simulation-based approximate identification of the mixing model, a heuristic approach was used that took into consideration multiple structures with changing mixing flows. A model of an advantageously smaller number of compartments and parameters was sought which satisfies the measured Residence Time Distribution.

The results suggest the intensive mixing of upper levels with a limitedly mixed lower part that contributes to the long tail of the RTD. The applied arrangement supports the horizontal distribution of the sugar beet slices to be digested and the multiple groups of bacteria. Moreover, limited vertical mixing helps to avoid the elutriation of the bacteria and undigested organic materials into the environment.

The suggested mixing model will be combined with the formerly elaborated model of the anaerobic fermentation process that consists of 9 groups of bacteria in our future work.

\section{Abbreviations}

$\begin{array}{ll}\text { ADM } & \text { Anaerobic Digestion Model } \\ \text { CFD } & \text { Computational Fluid Dynamics } \\ \text { ICP-OES } & \begin{array}{r}\text { Inductively Coupled Plasma Optical } \\ \text { Emission Spectroscopy }\end{array} \\ \text { IWA } & \text { International Water Association } \\ \text { NRMSE } & \text { Normalized Root Mean Square Error } \\ \text { PPS } & \text { Programmable Process Structures } \\ \text { RTD } & \text { Residence Time Distribution } \\ \text { TS } & \text { Total Solid content }\end{array}$

\section{Acknowledgement}

The authors are grateful for the financial support from the project EFOP-3.6.1-16-2016-00007.

\section{REFERENCES}

[1] Batstone, D.J.; Keller, J.; Newell, R.B.; Newland, M.: Modelling anaerobic degradation of complex wastewater. I: model development. Bioresour. Technol., 2000, 75, 67-74, DOI: 10.1016/S09608524(00)00018-3

[2] Batstone, D.J.; Keller, J.; Newell, R.B.; Newland, M.: Modelling anaerobic degradation of complex wastewater. II: parameter estimation and validation using slaughterhouse effluent. Bioresour. Technol., 2000, 75, 75-85, DOI: 10.1016/S0960-8524(00)00019-5

[3] Blumensaat, F.; Keller, J.: Modelling of two-stage anaerobic digestion using the IWA Anaerobic Digestion Model No. 1 (ADM1). Water Res., 2005, 39, 171-183, DOI: 10.1016/j.watres.2004.07.024

[4] Fezzani, B.; Cheikh, R.B.: Modelling of the mesophilic anaerobic co-digestion of olive mill wastewater with olive mill solid waste using anaerobic digestion model No. 1 (ADM1). Bioresour. Technol., 2008, 99, 6565-6577, DOI: 10.1016/j.biortech.2007.11.035

[5] Lauwers, J.; Appels, L.; Thompson, I.P.; Degrčve, J.; Impe, J.F.V.; Dewil, R.: Mathematical modelling of anaerobic digestion of biomass and waste: Power and limitations. Prog. Energ. Combust., 2013, 39, 383-402, DOI: 10.1016/j.pecs.2013.03.003

[6] Csukás, B.; Balogh, S.: Combining Genetic Programming with Generic Simulation Models in Evolutionary Synthesis. Computers in Industry, 1998, 36, 181-197, DOI: 10.1016/S0166-3615(98)00071-2 
[7] Guillard, F.; Tragardh, C.: Modeling of the Performance of Industrial Bioreactors with a Dynamic Microenvironmental Approach: A Critical Review. Chem. Eng. Technol., 1999, 22, 187195, DOI: 10.1002/(SICI)1521-4125(199903)22:3<187::AIDCEAT187>3.0.CO;2-9

[8] Jourdan, N. et al.: Compartmental Modelling in chemical engineering: A critical review. Chem. Eng. Sci., 2019, 210, 115-196, DOI: doi.org/10.1016/j.ces.2019.115196

[9] Norregaard, A. et al.: Hypothesis-driven compartment model for stirred bioreactors utilizing computational fluid dynamics and multiple $\mathrm{pH}$ sensors, Chem. Eng. J., 2019, 356, 161-169, DOI: 10.1016/j.cej.2018.08.191

[10] Kamarad, L.; Pohn, S.; Bochmann, G.; Harasek, M.:
Determination of mixing quality in biogas plant digesters using tracer tests and Computational Fluid Dynamics. Acta Univ. Agric. Silvic. Mendelianae Brun., 2013, 61(5), 1269-1278, DOI: 10.11118/actaun201361051269

[11] Varga, M.: Economic optimization of sustainable complex processes (model based optimization under uncertain cost parameters for industrial scale anaerobic fermentation of sugar beet slice). $P h D$ thesis, Kaposvár University 2009, (in Hungarian)

[12] Csukás, B.; Varga, M.: Préselt répaszelet anaerob fermentációján alapuló biogáz előállítás számítógépi modellezésének előzetes vizsgálata. 2008. Témajelentés. Folyamatinformatika Kutató Fejlesztó Bt., Kaposvár (in Hungarian) 